\title{
LCN2 Promoter Methylation Status as Novel Predictive Marker for Microvessel Density and Aggressive Tumor Phenotype in Breast Cancer Patients
}

\author{
Phanni bhushann Meka ${ }^{1}$, Sarika Jarjapu ${ }^{1}$, Santhoshi Rani Nanchari ${ }^{1}$, Sandeep \\ Kumar Vishwakarma ${ }^{2}$, Prajitha Mohandas Edathara ${ }^{1}$, Manjula Gorre ${ }^{1}$, \\ Anuradha Cingeetham ${ }^{1}$, Sugunakar Vuree ${ }^{1}$, Sandhya Annamaneni ${ }^{1}$, Nageswara \\ Rao Dunna ${ }^{3}$, Srinivasulu Mukta ${ }^{4}$, Triveni $B^{4}$, Vishnupriya Satti ${ }^{1 *}$
}

\begin{abstract}
LCN2 (Lipocalin 2) is a $25 \mathrm{KD}$ secreted acute phase protein, reported to be a novel regulator of angiogenesis in breast cancer. Up regulation of LCN2 had been observed in multiple cancers including breast cancer, pancreatic cancer and ovarian cancer. However, the role of LCN2 promoter methylation in the formation of microvessels is poorly understood. The aim of this study was to analyze the association of LCN 2 promoter methylation with microvessel formation and tumor cell proliferation in breast cancer patients. The LCN2 promoter methylation status was studied in 64 breast cancer tumors by methylation specific PCR (MSP). Evaluation of microvessel density (MVD) and Ki67 cell proliferation index was achieved by immunohistochemical staining using CD34 and MIB-1 antibodies, respectively. LCN2 promoter unmethylation status was observed in $43(67.2 \%)$ of breast cancer patients whereas LCN2 methylation status was seen in 21 (32.8\%). Further, LCN2 promoter unmethylation status was associated with aggressive tumor phenotype and elevated mean MVD in breast cancer patients.
\end{abstract}

Keywords: Lipocalin 2 - DNA methylation - microvessel density - cell proliferation - breast cancer

Asian Pac J Cancer Prev, 16 (12), 4965-4969

\section{Introduction}

Epigenetic alterations defined as heritable changes in gene expression that occur without alterations in underlying DNA sequences, play an essential role in normal development and carcinogenesis. In addition to the genetic alterations like chromosome rearrangements, point mutations and deletions, epigenetic changes have a crucial role in the initiation of malignant tumor and their progression. These epigenetic changes are commonly mediated by several mechanisms which include DNA methylation, histone modifications and abnormal expression of non-coding RNAs. Several studies had suggested that promoter DNA methylation plays an important role in disease development and regulation of gene expression or transcriptional silencing of the corresponding genes ( Hafez et al, 2015; Place et al., 2013; Han et al., 2013; Yuan et al., 2003). Moreover, DNA hypomethylation is known to be associated with activation of proto oncogenes whereas DNA hypermethylation is frequently associated with inactivation of tumor suppressor genes (De et al., 2004; Jovanovic et al., 2010).
LCN2 (Lipocalin2) or Neutrophil Gelatinase Associated Lipocalin (NGAL) is a $25 \mathrm{KD}$ secreted protein, plays an important role in innate immunity and in pathogenesis of several diseases (Pitashny et al., 2007; Viau et al., 2010 ). Elevated LCN2 expression had been reported in human epithelial cancers including breast, ovarian, colorectal and pancreatic cancers; however, the biological functions of LCN2 in tumor cells is yet to be elucidated (Nielsen et al., 1996; Bartsch et al., 1995; Lim et al., 2007; Stoesz et al., 1998). LCN2 expression was associated with lymph node positive status, poor histological grade and found to be an independent prognostic marker for decreased survival in breast cancer (Bauer et al., 2008). Moreover, the involvement of LCN2 in epithelial to mesenchymal transition and tumor progression was also reported in advanced breast cancer (Yang et al., 2009).

Off late, LCN2 is being considered as novel regulator of angiogenesis, since VEGF levels were found to be elevated with increased LCN2 expression (Yang et al., 2013). Earlier studies had demonstrated that over expression of LCN2 was associated with increased

${ }^{1}$ Department of Genetics, Osmania University, ${ }^{2}$ Deccan College of Medical Sciences, Kanchanbagh, ${ }^{4}$ MNJ Institute of Oncology \& Regional Cancer Centre, Hyderabad, ${ }^{3}$ School of Chemical \& Biotechnology, Sastra University, Tamil Nadu, India *For correspondence: sattivishnupriya@gmail.com 
microvessel density (MVD) in breast tumors confirming the role of LCN2 in angiogenesis (Fernandez et al., 2005). Down regulation of LCN2 gene expression was correlated with aberrant promoter methylation in breast cancer cell lines (Roll et al., 2008) which revealed the possible relationship between epigenetic regulation and LCN2 gene expression in breast cancer. However, there are no reports on confirming role of $\mathrm{LCN} 2$ promoter DNA methylation in development of tumor microvessels and tumor cell proliferation. Hence, the present study has been planned to analyze the promoter methylation status of LCN2 gene and its influence on microvessel density and tumor cell proliferation in breast cancer patients. This is the first report from Indian population on the role of LCN2 promoter methylation in the development of tumor microvessel formation.

\section{Materials and Methods}

Patients and healthy subjects: A total of 64 primary breast cancer patients (Ductal carcinoma) were recruited in this study from MNJ Institute of Oncology and Regional Cancer Centre, Hyderabad, India. Tumor tissue samples were collected in RNAlater solution (Life technologies) from the patients who underwent surgery before chemo or radio therapy. Clinical information such as tumor grade, lymph node status, hormone receptor status (Estrogen Receptor, Progesterone Receptor, and Human Epidermal Growth Factor Receptor 2) and type of breast cancer was noted from tumor registry. Information on age at diagnosis, menopausal status was collected from patients through personal interview. Informed consent was taken from the all participants. This study was approved by institutional ethical committee, MNJ Institute of Oncology and Regional Cancer Centre, Hyderabad, India.

DNA isolation, Bisulfite treatment and Methylation specific PCR (MSP): Genomic DNA was isolated from tumor tissue samples by phenol chloroform method (Pikor et al., 2011). Bisulfite treatment of DNA was performed by using Epimark bisulfite conversion kit (New England Biolabs) according to the manufacturer's instructions. Primer sequences and Methylation Specific PCR (MSP) conditions were followed as previously described (Roll et al., 2008). and provided in Table $3.2 \mu \mathrm{g}$ of genomic DNA was used for sodium bisulfite treatment, which converts all unmethylated cytosines to uracils, whereas methylated cytosines remained unchanged. Two sets of primers specific to methylated and unmethylated target sequences were used in two PCR reactions. PCR products (273 bp product of both methylated and unmethylated) were separated on 3\% agarose gel electrophoresis (Figure 1).

Immunohistochemistry: Formalin fixed paraffin tissue blocks were prepared from each patient's sample. $4 \mu \mathrm{m}$ thick tissue sections were used for immunohistochemical analysis of Microvessel density (MVD) and Ki67 proliferation index. For assessment of microvessel density (MVD), tissue sections were stained with monoclonal mouse anti human CD34 (Biogenex) in 1:2 dilution. Briefly, after deparaffinization, tissue sections were incubated with $3 \%$ hydrogen peroxide in methanol. Then the tissue sections were incubated with anti human
CD34 antibody at $4^{\circ} \mathrm{C}$ for overnight. Further the slides were incubated for $30 \mathrm{~min}$ with biotinylated secondary antibody followed by streptavidin peroxidase and DAB (Diaminobenzidene) was used as chromogen (Tae et al., 2000). The determination of ki67 proliferation index was done by staining the tissue sections with MIB-1 (DAKO, Copenhagen, Denmark) antibody. The tissue sections were treated with $10 \mathrm{mM}$ citrate buffer for 15 min in a microwave oven. The slides were stained in auto immuno stainer TechMate 500 (DAKO) for an incubation time of $25 \mathrm{~min}$ with MIB-1 (1:100 dilutions). DAB (Diaminobenzidene) used as chromogen (Klintman et al., 2010; Taweevisit et al., 2010).

Evaluation of MVD and Ki67 index: Stained slides were examined using Olympus BX 61 light microscope. Clusters of CD34 stained endothelial cells or single endothelial cells were considered as a vessel. Vessel lumens were not counted. At first, slides were examined under low magnification (x40) to identify the area of highest vascularity (hot spots). 4 hot spots from each slide were identified and microvessels were counted in each hot spot of the slide at 200x. The mean number of microvessels from these hot spots was calculated (Figure 2: Slide A, and Slide B). Mann Whitney U test was used to determine the $\mathrm{p}$ value. Ki67 proliferation index was considered as positive, if more than $30 \%$ of nuclear staining was observed in tumor cells (Taweevisit et al., 2010). (Figure 3: Slide A, and Slide B)

\section{Results}

The demographic data of breast cancer patients was

Table 1. Demographic Data of Breast Cancer Patients

\begin{tabular}{|c|c|c|}
\hline Variables & $\mathrm{n}$ & $\%$ \\
\hline \multicolumn{3}{|l|}{ Age } \\
\hline$\leq 40$ & 14 & 21.8 \\
\hline$\geq 40$ & 50 & 78.1 \\
\hline \multicolumn{3}{|l|}{ Diet } \\
\hline Vegetarian & 20 & 31.2 \\
\hline Non vegetarian & 44 & 68.7 \\
\hline \multicolumn{3}{|l|}{ Lactation } \\
\hline Yes & 51 & 79.6 \\
\hline No & 13 & 20.3 \\
\hline \multicolumn{3}{|l|}{ Menopausal status } \\
\hline Pre & 39 & 60.9 \\
\hline Post & 25 & 39.1 \\
\hline \multicolumn{3}{|l|}{ Tumor grade } \\
\hline I \& II & 8 & 12.5 \\
\hline III \& IV & 56 & 87.5 \\
\hline \multicolumn{3}{|c|}{ Estrogen Receptor Status } \\
\hline Positive (+) & 16 & 25 \\
\hline Negative(-) & 48 & 75 \\
\hline \multicolumn{3}{|c|}{ Progesterone receptor status } \\
\hline Positive $(+)$ & 13 & 20.3 \\
\hline Negative (-) & 51 & 79.6 \\
\hline \multicolumn{3}{|l|}{ HER2 status } \\
\hline Positive (+) & 39 & 60.9 \\
\hline Negative (-) & 25 & 39.1 \\
\hline \multicolumn{3}{|l|}{ Nodal status } \\
\hline Positive (+) & 51 & 79.6 \\
\hline Negative(-) & 13 & 20.3 \\
\hline
\end{tabular}


LCN2 Promoter Methylation Status as a Marker for Microvessel Density and Aggressive Behaviour in Breast Cancer Patients Table 2. Association between LCN2 Methylation Status and Clinicopathological Variables

\begin{tabular}{|c|c|c|}
\hline \multirow[t]{2}{*}{ Parameter } & Methylated n (\%) & Unmethylated n (\%) \\
\hline & $21(32.8)$ & $43(67.2)$ \\
\hline \multicolumn{3}{|l|}{ Microvessel density } \\
\hline & $10.98 \pm 2.20($ Mean $)$ & \multirow{2}{*}{$14.10 \pm 8.13$ ( Mean) } \\
\hline & $\mathrm{P}=0.16$ & \\
\hline \multicolumn{3}{|l|}{ Tumor grade } \\
\hline I\& II $\quad n=8$ & $5(62.5)$ & $3(37.5)$ \\
\hline III\&IV $\quad n=56$ & $16(28.6)$ & \multirow{2}{*}{$40(71.4)$} \\
\hline Yates $x^{2} ; p$ value & Yates $2=2.27, p=0.13$ & \\
\hline \multicolumn{3}{|l|}{ Nodal status } \\
\hline Positive $\quad n=51$ & $15(29.4)$ & $36(70.6)$ \\
\hline Negative $\quad n=13$ & $6(46.2)$ & \multirow{2}{*}{$7(53.8)$} \\
\hline $\mathrm{x}^{2} ; \mathrm{p}$ value & $\mathrm{x}^{2}=1.3 ; \mathrm{p}$ value $=0.25$ & \\
\hline \multicolumn{3}{|l|}{ ER Status } \\
\hline Positive & $8(50.0)$ & $8(50.0)$ \\
\hline Negative $\quad n=48$ & $13(27.1)$ & \multirow{2}{*}{$35(72.9)$} \\
\hline $\mathrm{x}^{2} ; \mathrm{p}$ value & $\mathrm{x}^{2}=2.85 ; \mathrm{p}$-value $=0.09$ & \\
\hline \multicolumn{3}{|l|}{ PR Status } \\
\hline Positive $\quad n=13$ & $4(30.8)$ & $9(69.2)$ \\
\hline Negative $\quad n=51$ & $17(33.4)$ & \multirow{2}{*}{$34(66.6)$} \\
\hline Yates $x^{2} ; p$ value & $\mathrm{x}^{2}=0.02 ; ; \mathrm{p}$ value $=0.87$ & \\
\hline \multicolumn{3}{|l|}{ HER2 Status } \\
\hline Positive $\quad n=39$ & $14(30.8)$ & $25(64.1)$ \\
\hline Negative $\quad n=25$ & $7(28.0)$ & \multirow{2}{*}{$18(72.0)$} \\
\hline $\mathrm{x}^{2} ; \mathrm{p}$ value & $\mathrm{x}^{2}=0.43 ; \mathrm{p}$ value $=0.51$ & \\
\hline Triple negative (TNBC) & $2(9.52)$ & $9(20.93)$ \\
\hline \multicolumn{3}{|l|}{ Menopausal status } \\
\hline Pre $\quad n=39$ & $15(38.5)$ & $24(61.5)$ \\
\hline post $n=25$ & $6(24.0)$ & \multirow{2}{*}{$19(76.0)$} \\
\hline $\mathrm{x}^{2} ; \mathrm{p}$ value & $\mathrm{x}^{2}=0.86 ; \mathrm{p}$ value $=0.35$ & \\
\hline \multicolumn{3}{|l|}{ Ki 67 index } \\
\hline Positive & $17(48.6)$ & $18(51.4)$ \\
\hline Negative $\quad n=29$ & $4(13.8)$ & \multirow{2}{*}{$25(86.2)$} \\
\hline Yates $x^{2} ; p$ value & $\mathrm{x}^{2}=7.19 ; \mathrm{p}$ value $=0.007$ & \\
\hline
\end{tabular}

Table 3. Primer sequences of LCN2 for Methylation Specific PCR

LCN2 Methylated

\section{Forward primer:}

Reverse primer:

LCN2 Unmethylated

Forward primer:

Reverse primer:

\author{
5'-CGA-GAG-TTA-TTG-CGT-TTA-GTC-GA \\ 5'-CGA-ATA-AAT-CAC-GAA-ATC-AAAAAT-TCG-A $\left(\mathrm{Tm}=60^{\circ} \mathrm{C}, 35\right.$ cycles, 273 bp product) \\ 5'-AGA-GTT-ATT-GTG-TTTAGT-TGA-GGA, \\ 5'-CAA-ATA-AAT-CACAAA-ATC-AAA-AAT-TCA-A $\left(\mathrm{Tm}=55^{\circ} \mathrm{C}, 35\right.$ cycles, 273 bp product)
}

given in Table $1.78 .12 \%$ of breast cancer patients were above the age of 40 years at the time of diagnosis and $60.9 \%$ of patients' were pre menopausal. $87.5 \%$ of breast cancer cases were in advanced stage and were found to be node positive $(79.6 \%)$. The association between promoter methylation of LCN2 gene and the clinical characteristics of breast cancer patients was summarized in Table 2. LCN2 promoter unmethylation was observed in $43(67.2 \%$ ) cases, whereas promoter methylation was found in $21(32.8 \%)$ cases. Promoter unmethylation was more often seen in patients with post-menopausal breast cancer $(76.0 \%)$, advanced stage tumors $(71.4 \%)$, ER 


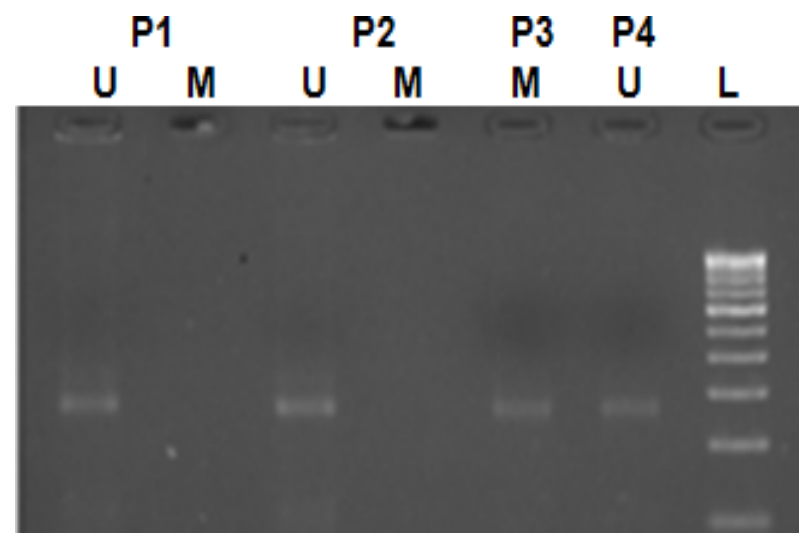

Figure 1. Gel Picture: LCN2 Promoter Methylation and Unmethylation (273bp). P- patient, U- Unmethylated, M- Methylated, L- Ladder (100bp)

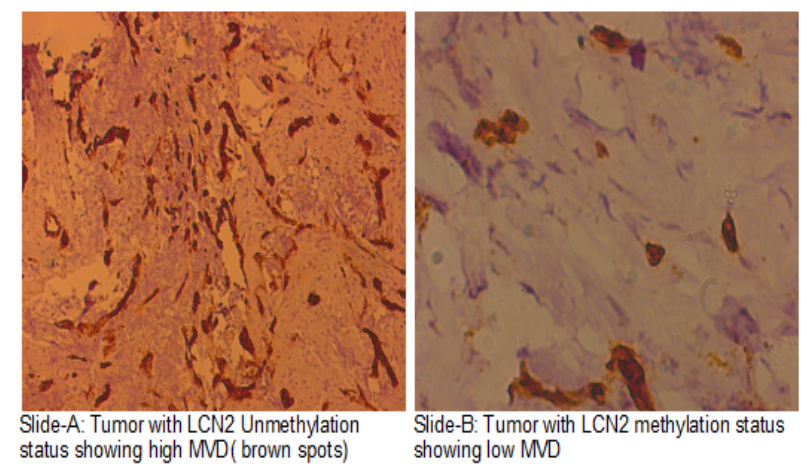

Figure 2. Immunohistochemical Staining of CD34 for Assessment of Microvessel Density in Bensity in Breast Tumors

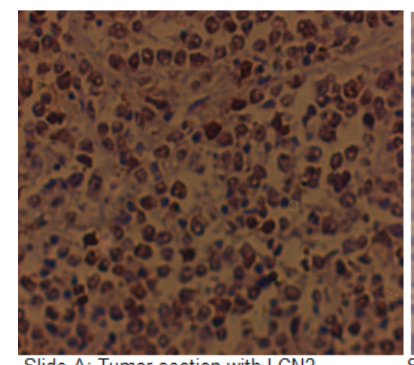

Slide A: Tumor section with LCN2 unmethylation status showing high ki67 proliferation

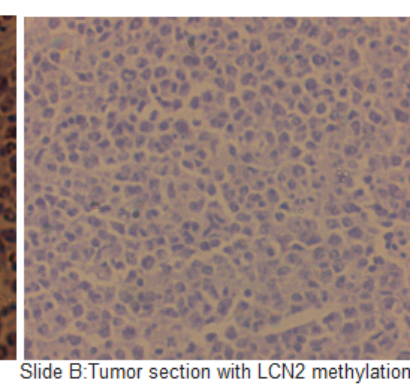

status showing low ki67 proliferation.

\section{Figure 3.Immunohistochemical Determination of Ki67 Proliferation}

(72.9\%), PR (66.6\%) and HER2 (72.0\%) negative breast tumors. $20.93 \%$ of triple negative breast cancer patients were observed with LCN2 unmethylated status. LCN2 promoter unmethylation was also observed in $86.2 \%$ of ki67 negative breast cancer patients.

Further we analyzed the association between LCN2 promoter methylation and tumor microvessel density in breast cancer tumors. The mean MVD was elevated in LCN2 unmethylated patients compared to methylated breast cancer patients though the difference was statistically insignificant. (Methylated; $10.98 \pm 2.20$, unmethylated; $14.10 \pm 8.13, \mathrm{p}=0.16$ )

\section{Discussion}

Angiogenesis is crucial process through which the solid tumor cells obtain oxygen and nutrients for their growth and dissemination. Hence, the blocking of angiogenesis by targeting the essential pro angiogenic growth factor (VEGF) was considered as an attractive strategy to control tumor progression (Harper et al., 2006). However, resistance to anti- VEGF therapy is often witnessed in solid tumors which emphasizes the need for targeting additional angiogenesis regulatory genes to overcome the challenges in anti-angiogenic cancer therapy (Gerald et al., 2012). The over expression of LCN2 gene, a novel angiogenesis regulator in human breast cancer, (Yang et al., 2013) had been associated with neovascularization, tumor growth and tumor cell proliferation (Fernandez et al., 2005). Although the expression patterns of LCN2 gene had been extensively studied in several cancers, the role of promoter methylation of LCN2 gene in the progression of breast cancer remains obscure.

In our study, LCN2 promoter unmethylation was found in 43 of $64(67.2 \%)$ breast cancer patients. Mean MVD was increased in patients with unmethylated LCN2 compared to methylated LCN2 patients. This might be due to the activation of LCN2 gene through promoter DNA unmethylation which resulted in elevated expression of LCN2 that might promote microvessel formation leading to angiogenesis so that tumor cells can survive. It was documented earlier by Roll et al., 2008 that LCN2 expression was dysregulated by aberrant promoter methylation in breast cancer cell lines indicating the possible role of epigenetic events in the expression of LCN2 gene. Further, promoter unmethylation of LCN2 was significantly associated with aggressive tumor phenotypes such as advanced stage tumors (71.4\%), node positive status (70.6\%) and triple negative breast tumors which indicated that $\mathrm{LCN} 2$ promoter unmethylation may be associated with the aggressive tumor phenotypes and tumor progression. Perhaps, our results offer the convincing evidence for describing the relationship between LCN2 unmethylation and tumor angiogenesis in breast cancer. Previous studies had shown the possible involvement of promoter methylation in down regulation/ loss of expression of corresponding gene in several cancers ( Place et al., 2013; Han et al., 2013; Yuan et al., 2003). Further, LCN2 promoter unmethylation was observed in $86.2 \%$ of breast cancer patients who were negative for ki67 marker suggesting that LCN2 unmethylation may not have any exert influence on cell proliferation. Our results are in accordance with the reports of Lee et al., 2006 which suggested that LCN2 expression had no influence on cell proliferation. Thus, the effects of LCN2 on cell proliferation may be cell type specific. Taken together our data suggests that promoter methylation status of LCN2 gene might have a protective role in breast cancer patients. Moreover, LCN2 promoter methylation status might be a marker for predicting tumor angiogenesis in breast cancer patients.

\section{Acknowledgements}

This study was funded by University Grants Commission-Centre for Advanced Studies, Phase-II (UGC-CAS-II), New Delhi and DBT-OU-ISLARE. 
LCN2 Promoter Methylation Status as a Marker for Microvessel Density and Aggressive Behaviour in Breast Cancer Patients

Phanni bhushann Meka is thankful to UGC-CAS-II for providing fellowship.

We would like to thank MNJ Institute of Oncology and Regional Cancer Centre, Hyderabad for providing samples from the breast cancer patients.

\section{References}

Bartsch S, Tschesche H (1995).Cloning and expression of human neutrophil lipocalin cDNA derived from bone marrow and ovarian cancer cells. FEBS Lett, 357, 255-9.

Bauer M, Eickhoff JC, Gould MN, et al. (2008). Neutrophil gelatinase-associated lipocalin (NGAL) is a predictor of poor prognosis in human primary breast cancer. Breast Cancer Res Treat, 108, 389-97.

De, Loriot A, Boon T (2004). Promoter-dependent mechanism leading to selective hypomethylation within the 50region of gene MAGE-A1 in tumor cells. Mol Cell Biol, 24, 47814790.

Fernandez CA, Yan L, Louis, G, et al (2005). The matrix metalloproteinase-9/neutrophil gelatinase-associated lipocalin complex plays a role in breast tumor growth and is present in the urine of breast cancer patients. Clin Cancer Res, 11, 5390-5.

Gerald W, Prager Marina P, Matthias U, et al (2012). Angiogenesis in cancer: anti-VEGF escape mechanisms. Transl Lung Cancer Res, $\mathbf{1}, 1$.

Hafez MM, Al-Shabanah OA, Al-Rejaie SS, et al (2015). Increased hypermethylation of glutathione s-transferase p1,DNA-binding protein inhibitor, death associated protein kinase and paired box protein-5 genes in triple-negative breast cancer saudi females. Asian Pac J Cancer Prev, 16, 541-9.

Han LL, Hou L, Zhou MJ, et al (2013). Aberrant NDRG1 methylation associated with its decreased expression and clinicopathological significance in breast cancer. $J$ Biomed Sci, 20, 52 .

Harper J, Moses MA (2006). Molecular regulation of tumor angiogenesis: mechanisms and therapeutic implications. EXS, 96, 223-68.

Jovanovic J, Ronneberg JA, Tost J, et al (2010). The epigenetics of breast cancer. Mol Oncol, 4, 242-54.

Klintman M, Bendahl PO, Grabau D, et al (2010). The prognostic value of Ki67 is dependent on estrogen receptor status and histological grade in premenopausal patients with nodenegative breast cancer. Mod Pathol, 23, 251-9.

Lee HJ, Lee EK, Lee KJ, et al (2006). Ectopic expression of neutrophil gelatinase-associated lipocalin suppresses the invasion and liver metastasis of colon cancer cells. Int $J$ Cancer, 118, 2490-7.

Lim R, Ahmed N, Borregaard N. (2007). Neutrophil gelatinaseassociated lipocalin (NGAL) an early-screening biomarker for ovarian cancer: NGAL is associated with epidermal growth factor-induced epithelio-mesenchymal transition. Int J Cancer, 120, 2426-34.

Nielsen BS, Borregaard N, Bundgaard JR, et al. (1996). Induction of NGAL synthesis in epithelial cells of human colorectal neoplasia and inflammatory bowel diseases. Gut, 38, 414-20.

Pikor LA1, Enfield KS, Cameron H, et al (2011). DNA Extraction from Paraffin Embedded Material for Genetic and Epigenetic Analyses. J Vis Exp, 49, 2763.

Pitashny M, Schwartz N, Qing X, et al (2007). Urinary lipocalin-2 is associated with renal disease activity in human lupus nephritis. Arthritis Rheum, 56, 1894-903.

Place TL, Fitzgerald MP, Venkataraman S, et al (2013). Aberrant promoter $\mathrm{CpG}$ methylation is a mechanism for impaired PHD3 expression in a diverse set of malignant cells. PLoS ONE, 6, 14617.

Roll JD, Rivenbark AG, Jones WD, et al (2008). DNMT3b overexpression contributes to a hypermethylator phenotype in human breast cancer cell lines. Mol Cancer, 7, 15

Stoesz SP, Friedl A, Haag JD, et al (1998). Heterogeneous expression of the Lipocalin NGAL in primary breast cancers. Int J Cancer, 79, 565-72.

Tae K, El-Naggar AK, et al (2000). Expression of vascular endothelial growth factor and microvessel density in head and neck tumorigenesis. Clin Cancer Res, 6, 2821-8.

Taweevisit M, Keelawat S, Scott Thorner P. (2010). Correlation of microvascular density and proliferation index in undifferentiated nasopharyngeal carcinoma. Asian Biomedicine, 4, 315-21.

Viau A, El Karoui K, Laouari D, et al (2010). Lipocalin 2 is essential for chronic kidney disease progression in mice and humans. J Clin Invest, 120, 4065-76.

Yang J, McNeish B, Butterfield C, Moses MA. (2013). Lipocalin 2 is a novel regulator of angiogenesis inhuman breast cancer. FASEB J, 1, 45-50.

Yang J, Moses MA (2009). Lipocalin 2: A Multifaceted Modulator of Human Cancer. Cell Cycle, 15, 2347-52.

Yuan J, Luo RZ, Fujii S, et al (2003). Aberrant Methylation and Silencing of ARHI an imprinted tumor suppressor gene in which the function is lost in breast cancer. Cancer Res, $\mathbf{6 3}$, 4174-80. 